\title{
Critical Reflection and Common-Sense Beliefs
}

A Peircean Rapprochement

\section{Francesco Poggiani}

\section{(2) OpenEdition \\ Journals}

Electronic version

URL: http://journals.openedition.org/ejpap/1058

DOI: 10.4000/ejpap.1058

ISSN: 2036-4091

Publisher

Associazione Pragma

\section{Electronic reference}

Francesco Poggiani, «Critical Reflection and Common-Sense Beliefs », European Journal of

Pragmatism and American Philosophy [Online], IX-2 | 2017, Online since 22 January 2018, connection on 01 May 2019. URL : http://journals.openedition.org/ejpap/1058 ; DOI : 10.4000/ejpap.1058

This text was automatically generated on 1 May 2019.

\section{(c) $(1)$}

Author retains copyright and grants the European Journal of Pragmatism and American Philosophy right of first publication with the work simultaneously licensed under a Creative Commons AttributionNonCommercial-NoDerivatives 4.0 International License. 


\title{
Critical Reflection and Common- Sense Beliefs
}

\author{
A Peircean Rapprochement
}

Francesco Poggiani

\section{Introduction}

1 Many philosophers hold a double standard when it comes to the normative standing of doubt and belief. While they regard "believing at will" to be both impossible and irrational, they often find "doubting at will," by contrast, to be highly rewarding for any form of rational inquiry. In particular, they take it to be our moral obligation not only to question but also to suspend or discard those intellectual inclinations that cannot be "rationally grounded" - whether or not we can entertain any real doubt about them, and regardless of how irresistible they may appear.

2 According to an influential view, ${ }^{1}$ such "acritical" beliefs may not even be properly classified as beliefs. This is because genuine beliefs are thought to be essentially responsive to experiential input, which they can only be, according to this view, by regulating their behavioral output on the basis of clearly identifiable grounds. This is what makes them inherently normative even as they remain fallible; as opposed to our "uncontrollable" judgments, whose seemingly normative implications we can and ought to suspend. In what follows, I will introduce and elaborate on some aspects of C. S. Peirce's pragmatism in order to articulate an alternative conception of belief.

3 Peirce's opposition to Descartes' method of hyperbolic doubt reflects the former's conviction that, given the practical nature of a concept's meaningful implications, inquiry should begin from doubts that are actually capable of disrupting our otherwise settled practical inclinations (which include inclinations governing theoretical inquiry, of course). If, as we shall see, the sole purpose of inquiry is the fixation of belief, there is no point in trying to "fix" habits of mind that are in fact already settled. ${ }^{2}$ At the same time, it seems as if Peirce was not always willing to embrace such a thoroughly pragmatic conception of inquiry. Not only he went so far as to claim that "beliefs," regarded as dispositions upon 
which we are ready to act in everyday life, should not play any normative role in theoretical inquiry. ${ }^{3} \mathrm{He}$ also constantly emphasized the risk of regarding as true whatever we find ourselves irresistibly inclined to believe by pointing to the fleeting nature of many such irresistible, so-called "self-evident" beliefs. Thus, in the well-known essay in which he introduced his conception of inquiry, Peirce also criticized the "a priori" method for the fixation of belief: the idea that, in contrast to both the methods of "tenacity" and "authority," we ought to reason on the basis of our natural ways of thinking or "inward light of reason," as this is expressed by our duly considered feelings and inclinations.

The foregoing tension can be brought out with respect to the relationship between truth and conceivability. On the one hand, as I have already mentioned, Pierce was critical of the Cartesian requirement according to which inquiry should only begin from those propositions which we cannot conceivably doubt. Inquiry does and should, in addition, rely upon all those beliefs about which we do not entertain any genuine doubt. On the other hand, Peirce did not regard our incapacity to cast genuine doubts on any given belief as an indication of its validity. The inconceivability of a proposition's negation cannot be, in and of itself, a valid criterion for endorsing that proposition. As a criterion or method of inquiry, the "test of inconceivability" is not only unreliable but also highly deceptive.

If we cannot already imagine any way in which a proposition would be false, neither can we yet imagine any way of imagining it to be false. But for all that, the simplest little suggestion or information may at any moment put it into our power to imagine what no effort of thought could before enable us to imagine. (CP 2.30)

For instance, one could find it impossible to deny that a whole is greater than any one of its parts. And yet, as in the case of Columbus' egg, it takes a quite simple suggestion to realize that while the collection of even numbers is only one part of the entire collection of integers, the former is as great as the latter. "For every integer number there is a separate and distinct double; and thus the doubles are as many as the integer numbers. But these doubles are all even numbers; and so, the partial collection is as great as the whole collection." (CP 2.30). ${ }^{5}$

6 As a consequence, Peirce appeared ambivalent with respect to the degree of trust we should confer upon our intuitive judgments and natural inferences. There is indeed an interesting however rarely noted tension between Peirce's pragmatic conception of reasoning and his rejection of psychologism and the a priori method. In what follows, I argue that Peirce's "Critical common-sensism" is an attempt to resolve this tension by arguing that we should neither conclusively accept nor discard our "acritically indubitable" intellectual dispositions. Rather we must unreservedly rely on them for the sake of engaging in any form of rational inquiry. ${ }^{6}$ This is because, whether or not they are in fact (entirely) "true," such dispositions provide us with the conceptual means to articulate both the very idea of rational inquiry and the opportunities of engaging in its pursuit. If, whenever you inquire into something, you have a general sense of what you are up to, this is because, insofar as you reason at all, you are striving to achieve that kind of intellectual stability ("fixation") which is already vaguely provided by that "immense mass of cognition already formed, of which you cannot divest yourself [...] and who knows whether, if you could, you would not have made all knowledge impossible to yourself?" (EP2: 336).

7 Now, if deliberate reasoning aims at a thorough settlement of belief, this is because the aim of fixation is "constitutive" of belief itself, or intrinsic to its natural telos. 
Accordingly, the bulk of this essay (sections 4-6) consists in a defense of the claim that cognitive stability is the constitutive aim of believing something to be the case - and that "truth" can be regarded as partaking of such an aim only by expressing that more fundamental claim. More precisely, my thesis is that whenever you believe a proposition (or in order to believe it), you regard is as true with the aim of thereby accepting a thoroughly stable opinion.?

But if fixation is the constitutive aim of belief, our acritically indubitable judgments and inferences ${ }^{8}$ can be regarded as genuine beliefs. Consequently, our inability to become aware of a belief's rational grounds is not by itself a sufficient reason to discard its meaningful implications. Before arguing for this conclusion, however, we must understand more precisely how acritically indubitable beliefs emerge and what role do they play in practical reasoning (sections 2-3).

\section{Pragmatism and Self-Control}

Peirce thought of pragmatism as a "method of reflexion" based upon an investigation of the phenomena of self-control. At the same time, he argued that "Critical commonsensism" is a necessary "consequence" of Pragmatism. These claims are importantly connected and can be best understood in light of each other.

"Critical common-sensism" consists in the claim that there are widely endorsed "propositions and inferences" which resemble perceptual judgments in being "acritical" (non deliberate or self-controlled), our non-intellectual dispositions in being "instinctive" (see EP2: 346-54), and our deepest insights in being "invariably vague." By contrast, the pragmatic maxim requires us to clarify the meaning of a proposition $p$ by looking at its implications for self-controlled conduct, namely, by determining how I ought to act if I were to believe that $p$. Among such implications, there is the fact that rational selfcontrol eventually comes to an end in judgments and inferences we cannot help acting upon (which include but are not limited to our perceptual judgments). Such "acritically indubitable" beliefs can thus be regarded at once as deriving from ("consequences" of) a concept's pragmatic clarification and a legitimate basis for inquiry's further developments. ${ }^{9}$ This is the sense in which, according to Peirce, the pragmatic method of inquiry entails high respect for our intuitive or commonsensical judgments and inferences. In this section I will elaborate upon this connection between self-control and common sense in light of Peirce's conception of reasoning.

Writes Peirce in 1905:

The term 'reasoning' ought to be confined to such fixation of one belief by another as is reasonable, deliberate, self-controlled. A reasoning must be conscious; and this consciousness is not mere 'immediate consciousness' [...] but is in its ultimate nature (meaning in that characteristic element of it that is not reducible to anything simpler), a sense of taking a habit, or disposition to respond to a given kind of stimulus in a given kind of way. (5.540)

12 This conception of reasoning reflects the irreducible law-like generality involved in any rationally self-controlled resolution to think or act in one way or another - conversely, it points to what makes it impossible for us to understand any symbolic expression without taking up, consolidating, or modifying a habit of conduct.

Yet, Peirce continues, "the secret of rational consciousness is not so much to be sought in the study of this one peculiar nucleolus," namely self-conscious habit change, "as in the 
review of the process of self-control in its entirety" (EP2: 347). Given the density of the text in which it occurs, this passage could be understood in different ways. However, important clues are provided by what immediately follows it. After emphasizing the importance of imagination for the formation of habits, and its greater role in "logical" than "moral" self-control, Peirce writes: "Certain obvious features of the phenomena of self-control (and especially of habit) can be expressed compactly [...] by saying that we have an occult nature of which and of its contents we can only judge by the conduct that it determines." And to emphasize that he is talking of self-controlled conduct, Peirce adds: "According to the maxim of Pragmaticism, to say that determination affects our occult nature is to say that it is capable of affecting deliberate conduct [...]" (EP2: 347, emphasis added).$^{10}$ Now, what makes conduct deliberate?

As Peirce notes in the fifth of his 1903 Harvard lectures, since any rational inference involves a "qualitative approval" of the general class of arguments to which the inference belongs, it is our consciousness of the specific character of such an approval that makes the inference fully deliberate - even though we may not be able to resist our inclination to approve it. Accordingly, in 1905 Peirce writes that the pragmatic maxim "requires that in reasoning we should be conscious, not only of the conclusion, and of our deliberate approval of it, but also of its being the result of the premiss from which it does result, and furthermore that the inference is one of a possible class of inferences which conform to one guiding principle" (EP2: 348). Insofar as we are aware of the general guiding principle which guides our inferences, the latter can be rightly said to belong to a chain of deliberate or self-controlled reasoning. However, Peirce continues:

There are [...] cases in which we are conscious that a belief has been determined by another given belief, but are not conscious that it proceeds on any general principle. Such is St. Augustine's 'cogito, ergo sum.' Such a process should be called, not a reasoning but an acritical inference. Again, there are cases in which one belief is determined by another, without our being at all aware of it. These should be called associational suggestions of belief. (EP2: 348) ${ }^{11}$

Presumably, then, a review of "the process of self-control in its entirety" should include a reflection on the nature and function of such non-thoroughly transparent inferences and beliefs.

To begin with, one might find Peirce's classification of Augustine's mode of inference inaccurate. I agree with Peirce's implicit assumption that Descartes' well-known inference is but a generalization of Augustine's "Si fallor, sum." ${ }^{12}$ But the latter does seem to be based on a deliberate (self-conscious) mode of reasoning. As Augustine writes in his treatise on the theological virtues: "by not positively affirming that they are alive, the skeptics ward off the appearance of error in themselves, yet they do make errors simply by showing themselves alive; one cannot err who is not alive. That we live is therefore not only true, but it is altogether certain as well." The general guiding principle which governs the foregoing inference can be roughly formulated as follows: nobody can doubt a proposition whose truth must be presupposed by any attempt to deny it. That is, if (by reductio) I was mistaken in believing that I am alive, I would still be shown to be alive by the fact that I am mistaken. Whence it follows that I cannot be mistaken about the fact that I am alive.

Then why does Peirce claim that Augustine's inference is "acritical," namely, one in which "we are conscious that a belief has been determined by another given belief, but are not conscious that it proceeds on any general principle"? Peirce's thought, I contend, 
might point to the fact that the rational strength of Augustine's inference does not depend on any self-conscious guiding principle. Not only we may be unaware of any relevant principle governing the inference "si fallor, sum" in the act of drawing it, but also our subsequent justification might be less a description of our rational motivation for making that inference than an ad hoc rationalization. And yet our lack of awareness of the relevant guiding principle does not undermine the rational validity of the inference even though it does diminish the degree of self-control under which it can be performed. By contrast when I say, "The ground is wet; it must have rained," the rational validity of this inference does seem to depend on the vague apprehension of a more general principle, such as that every event must have a cause.

18 Augustine questioned the sincerity of those people (the "Academics") who wonder "whether a wise man should ever affirm anything positively lest he be involved in the error of affirming as true what may be false." The problem with such an "agnostic" approach could be expressed as follows. On the one hand, it legitimizes radical skepticism as a kind of default epistemological position against which all our criteria ought ideally to be measured. By so doing, it sets a standard that is widely found impossible to meet. On the other hand, the standard itself is not as innocent as it appears, at least insofar as it conflates the question of the normative standing of an inference with the question about the degree of self-control under which it can be performed (the kind of intellectual selfcontrol which would be undermined by not doubting those beliefs, however inescapable, that cannot be rationally grounded). As a consequence it misrepresents, not so much that "particular nucleolus" (and highest expression) of deliberative rationality which consists in the possibility of drawing self-consciously guided rational inferences, as "the process of self-control regarded in its entirety" - namely, regarded from the broader perspective which includes the emergence of self-controlled inquiry from, and its gradual fulfillment toward, what is beyond our power to control.

of course, "control may itself be controlled, criticism itself subjected to criticism; and ideally there is no obvious definite limit to the sequence." And now it seems as if we were stuck between the horns of the dilemma: either there is no rationally acceptable limit to the regress, or such a limit could only be found in a combination of (something like) "sense impressions" and "self-evident" or a priori guiding principles. Peirce rejects this dilemma:

If one seriously inquiries whether it is possible that a completed series of actual efforts should have been endless or beginningless [...] I think he can only conclude that (with some vagueness as to what constitutes an effort) this must be regarded as impossible. It will be found to follow that three are, besides perceptual judgments, original (i.e., indubitable because uncriticized) beliefs of a general recurrent kind, as well as indubitable acritical inferences. (EP2: 348)

One might find it odd to group such suspiciously dubbed "indubitable" beliefs and inferences together with our more straightforward and seemingly less objectionable perpetual judgments. But in fact, Peirce thought of perceptual judgments as belonging to our "original" set of beliefs precisely because they are "acritically indubitable." That is to say, what implicitly motivates us to classify a judgment as perceptual is precisely our incapacity to defend ourselves from its forceful insistence - our incapacity to resist it or withhold our assent to it. As Peirce writes in an unpublished manuscript, "I cannot doubt that what seems to be before my eyes does so seem" (R598:9, c.1902). Similarly, most of us cannot genuinely doubt, no matter how hard we try, non-strictly perceptual propositions 
such as "Fire burns the flesh," "There is order in nature" (CP 5.508), "I am not alone in the universe" (R598:10), and "On the whole, memory is trustworthy" (R598:9)."13

\section{The Basis of Pragmatism in the Doctrine of Common Sense}

21 I have argued that Peirce's focus on the notion of self-control expresses his desire to question, rather than endorse, the idea that the validity of an inference (or belief) is directly proportional to the degree of self-control under which it can be performed. This conclusion does not intend to minimize the crucial role played by fully deliberate processes in rational conduct. To the contrary, it follows from a more detailed examination of the nature and conditions of such processes. As Peirce points out, "the theory of Pragmatism was originally based, as anybody will see who examines the papers of November 1877 and January 1878, upon a study of the experience of the phenomena of self-control which is common to all grown men and women" (EP2: 348). As we read in another manuscript:

My original exposition of pragmatism, which those who seek to depreciate it limit to one article in the Popular Science Monthly of January 1878, although I have [...] protested to each one of them personally that the argument is incomplete and insufficient without the article of November 1877 in the same journal ["The Fixation of Belief"] [...] - in this original exposition, I laid down, in the very first place, the doctrine of Common Sense; namely, that there are some propositions that a man, as a fact, does not doubt; and what he does not doubt, he can, at most, make but a futile pretense to criticize." (EP2: 432-3)

Curiously, "The Fixation of Belief” (hereafter Fixation) contains only one explicit reference to "common-sense," and a negative one for that matter. And on a first reading of that essay, there is no trace of anything that might resemble an exposition or defense of the "doctrine of common-sense." Was Peirce thinking of another of his early papers? Given the detailed referencing in the foregoing passage, this would be implausible. As it turns out, a closer reading of the first part of Fixation enables us to make sense of Peirce's later remark.

The negative reference to common sense occurs at the end of a preliminary section on the nature and function of reasoning, at the apex of which we read: "A moment's thought will show that a variety of facts are already assumed when the logical question is first asked." The normative question about how we ought to reason incorporates within itself many implicit assumptions:

It is implied, for instance, that there are such states of mind as doubt and belief -
that a passage from one to the other is possible, the object of thought remaining the
same, and that this transition is subject to some rules by which all minds are alike
bound. As these are facts which we must already know before we can have any clear
conception of reasoning at all, it cannot be supposed to be any longer of much
interest to inquire into their truth or falsity. (EP1: 113)

What would be the point of reasoning about (the truth or falsity of) that which must be presupposed by all reasoning? Notice, however, that Peirce is not arguing from the "indispensability" of these facts to their incontrovertible truth. He is merely saying that, because we have to assume them in order to engage in any form of normative reasoning at all, it would be pointless to inquire into whether or not we ought to regard them as true. Besides it doesn't follow, from the fact that an inquiry into their truth cannot be "any 
longer of much interest," that these assumptions are uninteresting or insignificant in themselves:

On the other hand, it is easy to believe that those rules of reasoning which are deduced from the very idea of the process [those rules which can be derived from the above-seen assumptions about the process of inquiry] are the ones which are the most essential; and, indeed, that so long as [reasoning] conforms to these it will, at least, not lead to false conclusions from true premisses. In point of fact, the importance of what may be deduced from the assumptions involved in the logical question turns out to be greater than might be supposed [...]. (EP1: 113)

Whether or not the constitutive assumptions of normative reasoning are metaphysically correct, they are highly significant in their own right. Indeed, "it is easy to believe" that the guiding principles ("rules of reasoning") deduced by them are the safest and "most essential." Peirce's "Illustrations of the Logic of Science" considered as a whole, so far as I can understand, are precisely an attempt to show "the importance of what may be deduced" from the constitutive assumptions of normative reasoning. ${ }^{14}$ At any rate, presumably the first part of such "deduction" would have to consist in the articulation of those constitutive assumptions. Accordingly, the last preliminary section of the Fixation contains a discussion of the correlative notions of doubt and belief.

First, Peirce observes, "we, know when we wish to ask a question and when we wish to pronounce a judgment" in virtue of a "dissimilarity between the sensation of doubting and that of believing." But there is also a "practical" difference between doubt and belief, in that "the feeling of believing is a more or less sure indication of there being established in our nature some habit which will determine our actions. Doubt never has such an effect." Finally, a third point of difference is that "Doubt is an uneasy and dissatisfied state from which we struggle to free ourselves and pass into the state of belief; while the latter is a calm and satisfactory state which we do not wish to avoid" (W3: 247). In short, belief and doubt (1) are indicated by different sensations, (2) involve the presence and disruption of habits, and (3) are coeval with experiences of satisfaction and dissatisfaction.

27 It is only after the foregoing considerations that we find what we might regard as the actual introduction to the main bulk of Fixation. Peirce begins this new paragraph with the well-known claim: "the irritation of doubt causes a struggle to attain a state of belief. I shall term this struggle inquiry [...] That the settlement of opinion is the sole end of inquiry is a very important proposition" (W3: 247). Notice however that this proposition, which amounts effectively to a preliminary characterization of "the very idea of the process" of normative reasoning (and which motivates and sets the tone for the rest of Fixation and the other "illustrations"), follows entirely from the preceding articulation of "those facts which are already assumed when the logical question is first asked" - in particular, our common sense understanding of doubt and belief. Only on the "assumption" that doubt is "an uneasy and dissatisfied state from which we struggle to free ourselves and pass into the state of belief" does it make sense to define inquiry as aiming exclusively at the "settlement of opinion."

It follows that "the mere putting of a proposition into the interrogative form does not stimulate the mind to any struggle after belief. There must be a real and living doubt, and without this all discussion is idle" (W3: 248). But in order for us to be able to translate such doubts into normative questions - questions about how we ought to go about satisfying our doubts - we must be able to start from equally "real and living" beliefs not only perceptual judgments, but more generally all those acritically indubitable beliefs 
which make up our habitual and unproblematic, practical orientation to the world or "readiness to act." Without such a-critical orientation we could never experience any real and living doubt, because the latter consists precisely in the privation of one or more of those habits which (used to) make up the former. In other words, living doubts and thus truly critical questions can be experienced and pursued only in virtue of acritically indubitable beliefs. Peirce's oxymoronic expression "Critical Common-sensism," according to this interpretation, captures the paradox represented by such reciprocal entailment between critical suspicion and practical conviction. ${ }^{15}$

This concludes my explication of Peirce's retrospective remark to the effect that Fixation includes, "in the very first place," a defense of "the doctrine of Common Sense; namely, that there are some propositions that a man, as a fact, does not doubt; and what he does not doubt, he can, at most, make but a futile pretense to criticize." Such propositions, as we have seen, are not only necessary but also sufficient conditions for engaging in any form of rational inquiry. As Peirce writes, "an inquiry [...] has only to start with propositions perfectly free from all actual doubt. If the premisses are not in fact doubted at all, they cannot be more satisfactory than they are." (W3: 248).

\section{Motivational vs. Truth-directed Accounts of Belief}

Of course, Peirce's "doctrine of common sense" is deeply at variance with a recognizable strain of modern philosophical common sense. According to the latter, not only some propositions are indeed a good deal more satisfactory than those, if there are any, which we cannot help believing or inferring; but also, and relatedly, no cognitive attitude should be classified as an instance of "belief" unless it can be endorsed on the basis of clearly identifiable grounds. And in fact, as Peirce writes in the above mentioned negative remark, "common-sense, or thought as it first emerges above the level of the narrowly practical, is deeply imbued with that bad logical quality to which the epithet metaphysical is commonly applied" (W3: 246). Peirce's doctrine of common sense was an attempt to clear up the "metaphysical" quality of those so-called "critical" habits of mind which raise above the level of the narrowly practical. ${ }^{16}$ But is Peirce's attempt successful? Does it actually provide us with a more satisfactory account of rational inquiry?

Since Peirce's pragmatist conception of inquiry is based on his account of belief, we may reasonably assume the validity of the former to be dependent on the latter. And Peirce himself is quite explicit about that not only in Fixation, but also in many of his later remarks - central among which we find the well-known acknowledgment that "pragmatism is scarce more than a corollary" of Alexander Bain's definition of belief as "that upon which a man is prepared to act" (EP2: 399). On a first approximation, however, this definition sheds relatively little light on the distinctive nature of belief. All it says is that there seems to be a necessary connection between believing that $p$ and being disposed ("prepared") to act in light of $p$. But, as Peirce would be the first to point out, merely assuming something for the sake of argument is also connected to the practice of (theoretical) inquiry. And yet, there are important differences between the attitudes of believing and assuming a proposition. ${ }^{17}$

One might argue that a hypothesis can lead us to perform an experimental test only in conjunction with beliefs - concerning, for instance, the epistemic worth of the given hypothesis within the overall economy of inquiry. We could thus conclude that while 
believing, assuming, imagining, etc., are all different ways of accepting a proposition, or regarding it as true, belief is distinguished by other cognitive attitudes as the only kind of acceptance which has the power actually to motivate us to act. Of course, beliefs can lead us to act only under the realization of various other conditions, such as the presence of relevant desires and requisite motor skills. But the point of Bain's definition, if interpreted so as to indicate the distinctive nature of belief, is that belief is the only condition for motivation which is both cognitive (as opposed to factual or conative) and necessary.

According to the foregoing "motivational" conception of belief, as David Velleman explains, "all that's necessary for an attitude to qualify as a belief is that it dispose the subject to behave in ways that would promote the satisfaction of his desires if its content were true. An attitude's tendency to cause behavioral output is thus conceived as sufficient to make it a belief." (Velleman 2000: 255). ${ }^{18}$ For instance, if the content of my propositional attitude is "there is enough gas in the car to get home without refueling," and I have a desire to get home as soon as possible, that attitude qualifies as belief insofar as it disposes me, in conjunction with this desire, to drive home without stopping at a gas station. The belief may be false, of course, in which case it won't allow me to satisfy my desire to get home early. But all that is required by the motivational conception is that it would enable me to satisfy desires if its propositional content were true. What this conception doesn't require is that beliefs be defined as being "truth-directed" in any strong or non-tautological sense of that expression, as I will shortly explain.

Admittedly, this conception of belief has much in common with the pragmatist view of the relationship between belief and truth. William James, for instance, defined truth as "whatever proves to be good in the way of belief" (James 1919: 42), which seems to presuppose that belief can indeed be defined prior to and independently of the concept of truth. The latter is something that "happens to an idea," as he also wrote. Besides, conceiving of beliefs (or ideas) exclusively in terms of "behavioral output" seems a crucial step toward questioning what is viewed by many pragmatists as the unduly privileged status that has been traditionally accorded to the concept of (truthful) representation, by reinserting this concept within the broader experience of finding something to be good, useful, or satisfactory (in the broadest sense of these terms). Finally Peirce himself, after giving the above-seen definition of inquiry, emphasizes the superfluity of the idea of truth when it comes to defining the aim of inquiry. He writes:

The sole object of inquiry is the settlement of opinion. We may fancy that this is not enough for us, and that we seek, not merely an opinion, but a true opinion. But put this fancy to the test, and it proves groundless; for as soon as a firm belief is reached we are entirely satisfied, whether the belief be true or false. [...] The most that can be maintained is, that we seek for a belief that we shall think to be true. But we think each one of our beliefs to be true, and, indeed, it is mere tautology to say so. (W3: 248)

As Velleman points out, in bearing this tautological relation to the notion of truth, "belief is just like any other propositional attitude, since wishing entails wishing something to be true, hoping entails hoping something to be true [...] Hence the fact that believing entails believing-true doesn't set belief apart from other attitudes." (Velleman 2000: 247).

By contrast, Velleman favors a conception of belief whose constitutive relation to the truth does actually set it apart from other cognitive as well as conative attitudes. Believing, on his account, does not merely amount to accepting a proposition or regarding it as true, but accepting or so regarding it "with the aim of thereby accepting a 
truth" (Velleman 2000: 252), where "an acceptance has the aim of being the acceptance of a truth when it is regulated [...] in ways designed to ensure that it is true." This is what can explain, among other things, the difficulty of believing at will. While (a) assuming or (b) imagining a proposition to be true involves accepting a proposition for the sake of argument, or regardless of whether or not it is, in fact, true, (c) believing a proposition does not come that easy. The reason, according to Velleman, is that the aim with which we accept a proposition whenever we believe it is precisely the aim of (c) getting its truth value right, "by regarding the proposition as true only if it really is" (Velleman 2000: 252). And the success conditions of such an aim are more restrictive than those which are involved in the aims of (a) considering the validity of a certain argument or, say, (b) exploring the imaginary limits of our cognitive faculties.

Velleman's "truth-directed" conception implies that belief cannot be characterized exclusively by reference to its motivational role. In order for a cognitive attitude to be classified as an instance of belief, it is not enough for it to motivate us to act. It must also at the same time regulate our behavior "in ways designed to ensure" that its own propositional object is true - even though, as Velleman is careful to point out, our regulatory mechanisms are neither infallible (which accounts for the fact that our beliefs, as opposed to imaginings, can indeed be mistaken) nor do they need to operate in any overtly intentional or self-conscious way.

Accordingly, the main thrust of Velleman's argument consists in showing why the capacity to dispose a person to act is not, after all, a distinctive feature of belief. As he persuasively argues, only by "smuggling" truth-directedness into their motivational account can philosophers deceive themselves into thinking that motivation is sufficient to characterize belief. For instance, if Bain's above seen definition as "that upon which a person is prepared to act" seems to capture the most characteristic aspect of belief, it is because we tend to regard "action" as a synonym of realistic or goal-pursuing action action oriented toward the satisfaction of realistic goals in virtue of "truth-directed" cognitions about the means that are necessary to pursue them. By so doing, however, we are led to interpret all instances of self-conscious behavior as being similarly realistically motivated. But that is clearly a mistake not only with respect to the widespread (especially among young children) phenomenon of make-believe, which is less a case of "purposeful simulation" of a wishful scenario than acting it out of one's imagination, but also with respect to such "adult" behaviors as talking to ourselves and expressing our emotions through "body-images" (scratching our head when we are puzzled, clenching our fists in anger, yelling at the referee of a match we are watching on television, etc.).

In all these cases, as Velleman points out, "imagining can be characterized as having the same conditional disposition as belief; the only differences have to do with the satisfaction of the associated conditions." For instance, unlike ordinary beliefs, "most deliberate imagining is accompanied by countervailing beliefs" which "exert their own motivational force," competing "with that of the subject's imagination" (Velleman 2000: 272). Thus, after yelling at the television, we don't yell louder because the referee couldn't hear us. And when talking to ourselves, we usually lower our voice. Now, "the fact that we talk to ourselves under our breaths suggests that the inhibition against unrealistic motivation is selective: it prevents behavior that would be inconvenient or self-destructive, but it permits behavior that is harmless, despite being unrealistic" (Velleman 2000: 265). 

pragmatism might be superficially characterized as promoting a purely motivational conception of belief, there are at least two facts which countervail this impression when it comes to Peirce's account of inquiry. In the first place, theoretical inquiry does on his account have a distinctive aim - one which, as I have argued in the previous section, derives from Peirce's reflection on the constitutive assumptions of normative reasoning, especially the idea that a belief cannot fully realize itself without finding repose in a sort of doubt-free state of "fixation."

41 Furthermore, the classical pragmatists as a whole were quite sympathetic to the observation that ideas or propositions are never simply accepted - entertained, contemplated, etc. They are always accepted from a certain perspective, within a certain context, and for the sake of a more or less vaguely conceived purpose, where the aim of "fixation" or stability is only one among others. Thus, while I can entertain the idea of "being taller than I really am" for a variety of different purposes, I cannot believe this proposition, namely accept it with the aim of thereby accepting a thoroughly stable opinion. In order to do so, I would have to develop an attitude toward it which is unsettled by competing considerations - which, in this case, are made too plainly available by the believed proposition itself.

Finally, as I will argue in the next section, Peirce constantly emphasized the essential role of imagination in any form of intentional conduct. ${ }^{19}$ In particular, he was interested in what he thought to be an irreducible connection between imagination and theoretical inquiry. After exploring this connection, we will be able to answer the question of how Peirce's conception of belief differs from Velleman's, and why this difference is so significant.

\section{The Role of Imagination in the Formation of Belief}

When a man desires ardently to know the truth, his first effort will be to imagine what that truth can be. [...] there is, after all, nothing but imagination that can ever supply him an inkling of the truth. He can stare stupidly at phenomena; but in the absence of imagination they will not connect themselves together in any rational way. [...] It is not too much to say that next after the passion to learn there is no quality so indispensable to the successful prosecution of science as imagination. (CP 1.46-7)

This intuition is intimately related to Peirce's pragmatic maxim, which he defined as the "method" of tracing out "in the imagination the conceivable practical consequences, that is, the consequences for deliberate, self-controlled conduct - of the affirmation or denial of the concept" (4.6) which is to be clarified. While we might already be familiar with a given concept or proposition, the only way to make our vague ideas about it clearer (the only way to turn the concept into a conception, as we might also say) is to imagine ourselves believing or doubting (affirming or negating) that proposition within various conceivable circumstances and, on this basis, determine what habits of action we ought to endorse, modify, or discard.

Now, if we can engage in this kind of deliberate imagination of a belief's practical bearings, it is because belief is a habit of thought which is already to some extent "active in the imagination" - whereby clarifying it through the pragmatic maxim consists in further articulating its imaginary ("conceivable") implications. Peirce explains this point

European Journal of Pragmatism and American Philosophy, IX-2 | 2017 
by drawing a contrast between the habit of "putting my left leg into my trouser before the right" and a belief-habit such as that fire is dangerous. If I have the first kind of habits, "when I imagine that I put on my trousers, I shall probably not definitely think of putting the left leg on first. But if I believe that fire is dangerous, and I imagine a fire bursting out close beside me, I shall also imagine that I jump back." (CP 2.148). That is to say, while I may or may not be able to remember (imagine) the structure of my seemingly "automatic" or compulsive habits of conduct, a person simply cannot be said to believe anything or have an intellectual habit unless the imagination of relevant circumstances didn't prompt the imagination of the appropriate inferential conclusions. Imagination, in this sense, is an essential ingredient of all beliefs - it is, indeed, "what particularly distinguishes" it from other kinds of habit.

Of course, defining belief in terms of the imagination's role in its formation, operation, and explication does not yield an answer to Velleman's question about what distinguishes belief, not only from other kinds of habit but also from other cognitive attitudes such as assumption and imagination itself. Perhaps, however, if belief cannot be defined independently of imagination, neither might we be able to understand the latter independently of the former.

This may seem counterintuitive. Aren't we capable of imagining and (to some extent at least) acting upon things which we know to be utterly fantastic? There is no doubt about that. But the question is precisely what is it that we are doing whenever we engage in the activity of imagining things irrespectively of what we know (believe) to be the case. One possibility, in light of the foregoing, is to think of "mere" imagination as a kind of wishful laboratory for the formation and clarification of beliefs. According to this assumption, a child who make-believes to be a mother is exploring the limits and possibilities of that fictional world which surrounds her and is in several ways related to the actual world by which she is nonetheless aware to be constrained. A person who talks with herself may be going through the inherently dialogical process of making up her mind upon something. After all, "thinking always proceeds in the form of a dialogue - a dialogue between different phases of the ego - so that, being dialogical, it is essentially composed of signs" (CP 4.6). Finally, many of our non-communicative gestures may express nothing more (or less) than a somewhat ironical and self-defeating attempt to enact and defend ourselves from the impenetrability of our emotions.

This is not to say that all our imaginings are realistically motivated. On the one hand, our most realistic pursuits can never do without imagination, because they rely upon it for the formation and maintenance of the habits by which they are to be governed. On the other hand, imagination is not the thoroughly boundless activity we conceive it to be. Even our most purely "wishful" forms of thought (imaginings motivated by cravings for things we know or assume to be unattainable) usually entail more than pointless or "atelic" play of thought. Writes Peirce:

It is a familiar experience to every human being to wish for something quite beyond his present means, and to follow that wish by the question, "Should I wish for that thing just the same, if I had ample means to gratify it?" To answer that question, he searches his heart [...] He makes in his imagination a sort of skeleton diagram [...] of himself, considers what modifications the hypothetical state of things would require to be made in that picture, and then examines it, that is, observes what he has imagined, to see whether the same ardent desire is there to be discerned. (CP 2.227) 
51 That is to say, either there is such a degree of steadiness in our imagination, which implies a struggle however slight with something other than our imagining attitude, or there is nothing at all that we are imagining. And it is not just the initial formation of the imaginary hypothesis that entails this irreducibly dual experience of struggle and resistance. It is also our subsequent manipulation of the hypothesis that may lead us to become genuinely surprised by the effects of our mental experiments. ${ }^{22}$

\section{Peirce's Account of the Aim of Belief}

The foregoing discussion of the nature of imagination and its constitutive role for beliefformation enables us to cast new light on the question concerning the distinctive nature of belief. As we have seen above, Peirce's conception is similar to Velleman's when it comes to the idea that belief must have something like a constitutive aim. At the same time, it involves a possibly different understanding of such an aim. In some cases, the 
difference points to nothing deeper than a difference of perspectives. As Peirce writes in Fixation, "The feeling which gives rise to any method of fixing belief is a dissatisfaction at two repugnant propositions. But here already is a vague concession that there is some one thing which a proposition should represent." (EP1: 120) ${ }^{23}$ Conversely, the persuasion that truth-directedness alone enables us to explain the impossibility of believing at will reflects a concession to the reciprocal entailment between the truth and stability of our intellectual dispositions.

But there is at least one category of beliefs with respect to which the issue is not merely terminological. That is the case of what Peirce dubs "acritically indubitable" beliefs judgments and inferences we cannot help making and acting upon, despite our inability to grasp their rational grounds (whether these be guiding principles governing our inferences or ideas taken as premises of our judgments). The question is whether Velleman's truth-directed account would permit classifying such a-critical attitudes as beliefs. Now, insofar his account depicts belief as entailing a regulation "designed to ensure" the truth of its propositional object, indubitable beliefs do not seem to be able to fulfill this condition. Taking 'believing to be right in regarding something as true' as a condition of belief sanctions the impossibility "believing" a proposition without grasping its evidential grounds. If the notion of "fixation" is to characterize the distinctive aim of belief, we cannot rely on Velleman's idea of truth-directedness in order to explicate it.

Now, Velleman argues that once we agree to think of beliefs as being "constitutively regulated by input," it follows as a conceptual implication of this normative picture that truth and falsity are the requisite normative standards of belief. In other words, if beliefs, in order to count as such, must not only generate output but also be regulated on the basis of input, nothing but "truth" can be the aim toward which such a regulation is actually directed. He writes: "False beliefs are necessarily faulty or mistaken [...] antecedently to and independent of any untoward practical consequences." But now "the fact that beliefs are conceived do be faulty when false indicates that the regulation conceived to be constitutive of them is regulation for truth. Truth-directedness thus appears to be enshrined in our [normative] concept of belief." (Velleman 2000: 277-8).

Yet one might grant this conclusion while wanting to unpack the concept of truth so as to explain its intimate connection with belief. That is exactly Peirce's strategy ${ }^{24}$ If truth can be properly regarded as the aim of belief, it is because all our belief-like attitudes aim at a final and unconditional settlement. If a child is playing at being the mother of her baby doll, she probably won't care if you tell her that she is not enacting a truthful or objective conception of motherhood. But she will be intrigued if we joined her game by playing in a fundamentally different way, thus questioning her implicit understanding of how a mother should treat her own baby. Whether or not a person has mastered the concept of objective truth, her beliefs aim at that sort of stability which tends to be obstructed by conflicting opinions - especially if these come from significant others.

Indeed, as Peirce points out, a pragmatic clarification of the concept of truth, conceived as the property of beliefs whose objects are real, leads us to conclude that "the only effect which real things have is to cause [full-fledged or thoroughly stable] belief." That is to say, "the opinion which is fated to be ultimately agreed to by all who investigate, is what we mean by the truth, and the object represented in this opinion is the real." It follows that truth-directedness is "enshrined in our concept of belief" only in virtue of the conceptual mediation provided by the aim of a final, "predestined" settlement of opinion (or intellectual satisfaction). ${ }^{25}$ 
difference between rationally grounded and indubitable belief-habits does not consist in the "aim" by which they are regulated, but in the greater role played by selfcontrolled imagination in the formation and maintenance of the former. At the same time, only by leading us to satisfy those doubts which have been able to unsettle our otherwise stable mental inclinations can our imaginative variations contribute to the deliberate formation of rationally grounded beliefs. The constitutive aim of belief, accordingly, is to achieve the kind of intellectual stability which is already vaguely entailed by our acritically indubitable beliefs. ${ }^{26}$ To believe something amounts to accepting a proposition, or regarding it as true, with the aim of thereby establishing a thoroughly stable habit of conduct.

\section{Conclusion}

The foregoing conclusion might seem to contradict Peirce's insistence that our incapacity to doubt a proposition, or imagine ways in which it could be doubted, cannot be a conclusive reason for endorsing it. ${ }^{27}$ In light of the foregoing, however, we can draw the following distinction. It is one thing conclusively to accept a proposition on the ground of our incapacity to imagine how it could be false. Acknowledging a pervasive intellectual inclination and, after having clarified it through the pragmatic maxim, relying upon it on account of its continued insistence is quite another. As Peirce observes,

neither the philosophy of Common-Sense nor the man who holds it accepts any belief on the ground that it has not been criticized. For [...] such [acritical] beliefs are not "accepted." What happens is that one comes to recognize that one has had the belief-habit as long as one can remember; and to say that no doubt of it has ever arisen is only another way of saying the same thing. (CP 5.523)

It is the significance of this fact that Peirce was most interested in articulating.

In light of the foregoing, two ideas are worth emphasizing. There are certain ("acritically indubitable") beliefs which, regardless of whether or not they are in fact true, (1) give us a sense of what any intellectual habit would have to be like in order to develop in accordance with its natue telos. And, (2) insofar as they provide us with the very terms to articulate our doubts, such beliefs constitute the "first premises" of all cognitive inquiry. "This does not deny that what cannot be conceived today may be conceivable tomorrow. But just as long as we cannot help adopting a mode of thought, so long it must be thoroughly accepted as true" - hence trusted or relied upon. "Any doubt of it is idle make-believe and irredeemable paper." It follows that when Peirce says that a proposition which is not doubted at all cannot be more satisfactory than it is, he is not being hyperbolic. He is pointing to the fact that we can develop no coherent idea of the aim of inquiry in abstraction from those "perfectly self-satisfied" habits of action whose "privation" sets us in "a condition of erratic activity that in some way must get superseded by a [new] habit" (EP2: 336-7). Indeed, since those habits are "mostly (at least) unconscious," it is precisely in virtue of their interruption that we can become aware of the kind of satisfaction at which we aim.

61 Consequently, while the notion of "inconceivability" is problematic as a criterion of truth, it is perfectly legitimate and indeed necessary as an element of its definition (at least when it comes to the truth of necessary propositions). Writes Peirce in his Minute Logic (1902):

A reasonable disputant disputes because he hopes [...] that both parties will at length find themselves forced to a common belief which will be definitive and final. 
For otherwise, why dispute? To reach a final and compulsory belief is, therefore, what the reasonable disputant aims at. [...] If, then, you can prove to him that a necessary proposition is such that there will be a final, unshakable compulsion preventing him from imagining it to be false, you have proved to him that it has those characters which he expresses by saying that the proposition is true. (CP 2.29)

Even though "the history of science teems with inconceivabilities which have been conquered," the inconceivability of the opposite remains a definitive mark of the truth of necessary propositions. Only, it is required "that 'inconceivable' should mean not merely unrealizable in imagination today but unrealizable after indefinite training and education," or eternally so. By implication, even though contingent propositions can be imagined to be false, it is our critically endorsed incapacity seriously to entertain contrasting hypotheses that sets our belief-like attitudes toward those propositions apart from others.

One might object that, regardless of whether or not Peirce actually held this conception of belief, conceiving the latter as aiming at such a "compulsion" as would prevent us from regarding it to be false is not only deeply unattractive but also inherently self-defeating. While I cannot fully address this important objection in a few words, I want to say something about the idea that aiming to "settle" our opinions would lead us to deceive ourselves about their rational stability. Many people seem steadily attached to opinions which would become unstable the moment they began asking questions about their own meaning and implications. How, then, can aiming at a final compulsion of thought prevent our beliefs from undermining their rational vocation? If, as the objection goes, the aim of belief is supposed to explain their capacity to be "responsive to input," fixation seems exactly the kind of aim we would have to exclude from consideration. Either belief, as I conceive it, is irremediably self-defeating, or we must have hit upon a mistaken conception of them.

63 As it turns out, Peirce seemed to be well aware of this kind of objection. This is what, in my understanding, actually motivated his ironical selection of the "methods" for the fixation of belief. The first two methods - tenaciously clinging to our current beliefs and regarding their validity as being dependent upon ratification of a cultural or political authority - are based, at least in part, on the self-centered vices of laziness and fear. The "method of science," by contrast, is based on the virtues of courage and selfless dedication to an indefinitely prolonged course of experimentation. The irony can be expressed as follows: on the one hand, one could not find two attitudes more strikingly opposed to each other than believing something out of fear, or laziness, and indefinitely suspending one's belief for the sake of scientific inquiry. On the other hand, and this is the central point of Peirce's argument (as I read it), both attitudes are rooted in a common desire to "reach a final and compulsory belief" - whence it follows that the problem with the first two methods does not consist in aiming solely at a conclusive settlement of belief, but in not aiming at it passionately enough. What determines the failure of the first two methods, as we might also say, is a lack of imagination: an incapacity to imagine ways in which our belief-habit might break down under conceivable circumstances. But this, in turn, derives precisely from a sort of unwillingness to believe - or, which amounts to the same thing, from our willingness to settle for merely half-hearted or pretend beliefs. ${ }^{28}$

What deceives us into believing opinions which are genuinely doubtful is not our "will to believe." It is, on the contrary, our attempt to defend ourselves from such a thoroughly wishful, ${ }^{29}$ and yet seemingly ineradicable impulse. It is this desire to believe that should be seen as characterizing us as rational agents, namely as beings who can only fulfill their 
rational vocation by striving to act as they must. And there is no more effective and selfdeceiving way to defend ourselves from this drive toward "normative necessity" than aiming to think as we feel we should, which, in Peirce's classification, characterizes the third "a priori" method for the fixation of belief. The problem with this method does not consist in the high respect it pays to the "natural" development of our intellectual inclinations. Rather, the problem consists in our characteristically modern inability to see how such development can best be served by loving the truth (what we are fated to believe) more than our preconceptions about the conditions that would make our believing it rationally acceptable.

\section{BIBLIOGRAPHY}

AGLER David W., (2011), "Polanyi and Peirce on the Critical Method," Tradition and Discovery: The Polanyi Society Periodical, 38 (3), 13-30.

COLAPIETRO Vincent, (1999), “Peirce's Guess at the Riddle of Rationality: Deliberative Imagination as the Personal Locus of Human Practice," in Sandra B. Rosenthal, Carl R. Hausman \& Douglas R. Anderson (eds.), Classical American Pragmatism: Its Contemporary Vitality, Urbana, University of Illinois Press.

FABBRICHESI Leo Rossella, (2004), "Peirce and Wittgenstein on Common Sense," Cognitio, 5 (2), 180-93.

FRIEDMAN Lesley, (1999), "Doubt \& Inquiry: Peirce and Descartes Revisited," Transactions of the Charles S. Peirce Society, 35 (4), 724-46.

HAACK Susan, (1982), “Descartes, Peirce and the Cognitive Community,” The Monist, 65 (2), 156-81. ноокWAY Christopher, (2000), Truth, Rationality, and Pragmatism: Themes from Peirce, Oxford, Oxford University Press.

ноокWAY Christopher, (2012), The Pragmatic Maxim: Essays on Peirce and Pragmatism, Oxford, Oxford University Press.

JAMES William, (1919 [1907]), Pragmatism: A New Name for Some Old Ways of Thinking, Reprint, New York, Longmans, Green and Co.

KASSER Jeffrey L., (2011), “How Settled are Settled Beliefs in “The Fixation of Belief?," Transactions of the Charles S. Peirce Society: A Quarterly Journal in American Philosophy, 47 (2), 226-47.

LOEB Louis E., (1998), "Sextus, Descartes, Hume, and Peirce: On Securing Settled Doxastic States," Noûs, 32 (2), 205-30.

MADDALENA Giovanni, (2010), "Peirce's Theory of Assent," Ideas in Action, Helsinki, Nordic Studies in Pragmatism, 211-23.

MISAK Cheryl, (2016), Cambridge Pragmatism: From Peirce and James to Ramsey and Wittgenstein, Oxford, Oxford University Press. 
PEIRCE Charles S., (1960), Collected Papers of Charles Sanders Peirce, Cambridge, Belknap Press of Harvard University Press.

PEIRCE Charles S., (1982), Writings of Charles S. Peirce, Bloomington, Indiana University Press. PEIRCE Charles S., (1992), The Essential Peirce, Vol. 1, Bloomington, Indiana University Press. PEIRCE Charles S., (1998), The Essential Peirce, Vol 2, Bloomington, Indiana University Press. POGGIANI Francesco, (2012), “What Makes a Reasoning Sound?: C. S. Peirce's Normative Foundation of Logic," Transactions of the Charles S. Peirce Society: A Quarterly Journal in American Philosophy, 48 (1), 31-50.

POGGIANI Francesco, (2014), "Truth and Satisfaction: The Gist of Pragmaticism," in Torkild Thellefsen \& Bent Sorensen (eds.), Charles Sanders Peirce in His Own Words: 100 Years of Semiotics, Communication and Cognition (vol. 14), Walter de Gruyter GmbH \& Co, KG.

POLLOCK Ryan \& David W. AGLER, (2016), "Hume and Peirce on the Ultimate Stability of Belief,"

Pacific Philosophical Quarterly, 97 (2), 245-69.

SHAH Nishi \& James David velleman, (2005), "Doxastic Deliberation,” The Philosophical Review, 114 (4), 497-534.

SHORT Thomas L., (2000), "Peirce on the Aim of Inquiry: Another Reading of 'Fixation'," Transactions of the Charles S. Peirce Society, 36 (1), 1-23.

Velleman James David, (2000), The Possibility of Practical Reason, Oxford, Clarendon.

Velleman James David, (2004), “Replies to Discussion on 'The Possibility of Practical Reason'," Philosophical Studies: An International Journal for Philosophy in the Analytic Tradition, 121 (3), 277-98.

\section{NOTES}

1. I will discuss below one influential variant of this view, which, in contemporary epistemology, goes by the name of "evidentialism." Cheryl Misak is the most prominent among Peirce's scholars to propose an evidentialist reading of his conception of belief (see Misak 2016).

2. This account of Peirce's criticism of the Cartesian method is based on Susan Haack's pivotal study (1982).

3. "What is properly and usually called belief [...] has no place in science at all" (CP 1.635; RLT: 112).

4. Peirce defines a "criterion" as "a method of experiment by which something is ascertained which is a sure indication of whether or not something different, and less easy otherwise to find out, is true" (CP 2.29).

5. "The difficulty is that the opinions which today seem most unshakable are found tomorrow to be out of fashion. They are really far more changeable than they appear to a hasty reader to be." (CP 5.382n).

6. Christopher Hookway (2000) has interpreted the "critical" nature of Peirce's endorsement of common sense along similar lines. He writes: "It thus seems that we should try to doubt propositions that seem self-evident; and, even if they escape criticism, we must allow that they could still succumb in the future. In these remarks we find the germs of 'critical' common-sensism." (Hookway 2000: 204). I will argue that, in order to make sense of such critical emphasis without sinking back "into a Cartesian mire 
from which [Peirce's] common-sensism was supposed to offer escape (209), such a "high esteem for doubt" (5.514) should be placed within the broader context of Peirce's conception of belief. In other words, in order to understand what makes Peirce's philosophy of common sense critical, we must first come to terms with his esteem for common sense beliefs.

7. Cf. Kasser 2011.

8. As we shall see below, Peirce distinguishes between "acritical inferences" and "associational suggestions of belief." Since belief is itself, on his own account, a habit of mind, the relevant difference might be more properly expressed as one between acts (as opposed to attitudes): the act of judging $x$ to be the case, without being aware of $x$ 's grounds, and the act of inferring $x$ from $y$, without being aware of any relevant inferential principle. In what follows, I will often use the term indubitable belief somewhat loosely to indicate both acritical judgments and inferences. While the difference between such acts does not have any immediate implication for my argument, it fits nicely with the picture of self-control I will provide below, according to which selfcontrol is a matter degree of awareness of our beliefs' normative grounds.

9. Evidence for this admittedly tentative interpretation of the connection between pragmatism and critical common-sensism can be gathered by the following passage. "That veritably indubitable beliefs are especially vague could be proved a priori. But proof not being aimed at today, it will be simpler to say that the Critical Common-sensist's personal experience is that a suitable line of reflexion, accompanied by imaginary experimentation, always excites doubt of any very broad proposition if it be defined with precision. Yet there are beliefs of which such a critical sifting invariably leaves a certain vague residuum unaffected." (5.507).

10. This might sound surprising. Doesn't the character of our "occult nature," at least in some important cases, emerge more clearly in those actions which are, so to speak, brought about despite our effort to control them? Isn't "who we truly are" more clearly and honestly revealed by what we end up doing "when the chips are down," regardless of our previous deliberation on the relevant issues? But in fact, Peirce's point is that there is a much more intimate connection between human nature and self-control than we are inclined to think. Of course, if by nature we mean whatever we are in abstraction from the desire to act (or constitute ourselves) as we ought, Peirce's remark does indeed sound implausible. But given the often emphasized centrality of the idea of deliberative freedom for an adequate understanding of human agency, it is that terminological stipulation which should be questioned. Be that as it may, for the purpose of arriving at a more accurate understanding of (practical) rationality, the most important anthropological question is what to think of our "occult nature" once we acknowledge the primacy of the deliberative perspective.

11. In a rejected manuscript page, Peirce explains: "It should be understood that Common-sensism recognizes two classes of indubitable, which, because they are indubitable, are uncriticizable. The one class consists of propositions of whose falsity one cannot imagine any case. The other class consists of conscious determinations of one belief by another, without any consciousness of any principle guiding the causation. Such is St. Augustine's Cogito, ergo sum. I do not call these reasonings, but I call them acritical inferences; for there has always been a tendency to use inference in a wider sense than reasoning. It is of the essence of reasoning to be reasonable, deliberate, self-controlled. To that end, it must recognize and approve [its own guiding] principle. In acritical inference 
one is quite conscious that it is that which the premiss asserts which renders the conclusion evidently certain or probable, as the case may be." (R290:16X-17).

12. See De Civitate Dei, Book XI.

13. The important question remains as to what is it, specifically, that moves us to regard only some of our indubitable beliefs as perceptual, as opposed to intellectual, volitional, etc. But whatever the answer to that question, we cannot appeal to any more original contact with reality than whatever is already afforded by the foregoing experience of "brute" reaction. In the end, our sense that "perceptual judgments" are capable of reflecting more directly the appearances of a reality which surrounds us might be due to the cultural prevalence of a quite narrow or univocal conception of reality.

14. Christopher Hookway proposes a similar reading of Peirce's Illustrations considered as a whole (see Hoowkay 2000: 35).

15. My reading of Peirce, in this respect, is influenced by the epistemological insights of Michael Polanyi. For a comparison between Pierce and Polanyi's criticisms of the "critical method," see Agler 2011.

16. The purpose of this paper is not to give a full account of what makes Peirce's common-sensism critical. I rather want to show why Peirce's critical common-sensism is not an attempt to strike a balance between Descartes' method Thomas Reid's philosophy of common sense. On the one hand, a "mark of the Critical Common-sensist is that he has a high esteem for doubt. He may almost be said to have a sacra fames for it. Only, his hunger is not to be appeased with paper doubts: he must have the heavy and noble metal, or else belief." (CP 5.514). On the other hand, our capacity to distinguish between paper and genuine doubts cannot be taken for granted. Part of the problem is that what might appear as genuine doubts often result from inadequate common sense "critical" presuppositions about the way in which we ought to think - this is, among other things, what grounds the need for a truly critical approach to common sense.

17. For an insightful account of Peirce's distinction between practical and theoretical belief, see Hookway (2000: 21-43).

18. Velleman's more sophisticated view, in Shah \& Velleman 2005. I will focus on Velleman's original exposition because it is more immediately relevant to the purposes of this essay.

19. The following account of the centrality of imagination in deliberate processes of belief formation is deeply indebted to Vincent Colapietro's influential work. See, for instance, Colapietro 1999.

20. T. L. Short reads Peirce in a similar vein: "Normative questions arise naturally, and they are not reducible to questions of fact. They do not reduce to questions of fact, because their resolution depends on human choice. But human choices, though they can be arbitrary, cannot be sustained regardless of human nature or regardless of the nature of the world in which we exist." (Short 2000: 10).

21. "A mere imagination of reacting in a particular way seems to be capable after numerous repetitions of causing the imagined kind of reaction really to take place upon subsequent occurrences of the stimulus. In the formation of habits of deliberate action, we may imagine the occurrence of the stimulus, and think out what the results of different actions will be. One of these will appear particularly satisfactory; and then an action of the soul takes place which is well described by saying that that mode of reaction 'receives a deliberate stamp of approval.' The result will be that when a similar occasion actually arises for the first time it will be found that the habit of really reacting in that way is already established." (CP 5.538). 
22. See CP 5.567.

23. Consider also the following passage from Fixation: "what is more wholesome than any particular belief is integrity of belief, and [...] to avoid looking into the support of any belief from a fear that it may turn out rotten is quite as immoral as it is disadvantageous" (EP1: 123).

24. As Short points out, the strategy of Peirce's argument, in Fixation, is to begin from denying that "truth" has anything to do with the aim of inquiry only in order to "bring out the basis on which we have made impersonal truth inquiry's aim, and on which we ought to continue doing so" (Short 2000: 9).

25. See Poggiani 2012 and 2014.

26. In this connection, Peirce writes: "It is easy to be certain - he writes - one has only to be sufficiently vague." (CP 4.237). For an excellent overview of the way in which Peirce's understanding of common sense beliefs relates to Wittgenstein's, see Fabbrichesi 2004. Cf. also Maddalena 2010.

27. For an insightful account of Peirce's rejection of psychologism, see Hookway 2012. 28. This conclusion is consistent with, and partly inspired by, Lesley Friedman's account of Peirce's critique of the Cartesian "psychological strategy necessary for suspending those claims about which we have a firm conviction" (Friedman 1999: 725).

29. In this connection, it might be helpful to emphasize Peirce's insistence that inquiry be based on a "hope" that it will eventually achieve its purpose. And if inquiry can, in fact, be motivated by nothing more substantial than such a hope, then perhaps we should revise our common sense understanding of the relationship between hope and certainty. See, for instance, CP 7.78. For an insightful account of Peirce's "optimism" about the objective of inquiry, see Loeb 1998. But cf. Pollock \& Agler 2016.

\section{ABSTRACTS}

I explore the connection between pragmatism and common sense by reflecting upon two seemingly contrasting Peircean remarks about the pragmatic method: (a) its "basis on the doctrine of common sense" and (b) the recommendation that a proposition $p$ be explicated in light of critical, deliberate, or "self-controlled" conduct ensuing from a belief that $p$. I show that Peirce's focus on phenomena of self-control is situated within his broader interest in the nature of reasoning. The "secret of rational consciousness," according to Peirce, does not consist in the reflective or self-conscious nature of our most deliberate forms of conduct, per se, "as in the review of the process of self-control in its entirety." The rationality of an inference consists in its capacity to restore the stability our "acritical" beliefs enjoyed before being unsettled by doubts. On this view, Peirce's pragmatic theory of rational inquiry as aiming at the fixation of belief depends on a conception of belief as constituted by a tendency toward stability. In the rest of the paper, I argue that this conception avoids the shortcoming of purely "motivational" accounts of belief without denying this status of belief to our acritical intellectual dispositions - a denial which is often implied by standard "truth-directed" accounts. 


\section{AUTHOR}

FRANCESCO POGGIANI

Pennsylvania State University

fup109[at]psu.edu 